\title{
Comentario No1 "Seguel con Fisco de Chile"
}

\author{
José Miguel Valdivia \\ Profesor de Derecho Administrativo \\ Universidad Adolfo Ibáńez.
}

1. El interés principal de la sentencia Seguel reside la fundamentación que articula para hacer responsable al Estado por la falta de servicio en que incurren organismos militares. Reconociendo explícitamente la existencia de una falta de servicio, la Corte Suprema acude a las reglas tradicionales de responsabilidad extracontractual contenidas en el Código Civil para condenar al Fisco.

El pronunciamiento tiene sobre todo significación textual. Hasta ahora, las instituciones militares (del mismo modo que las policiales) se encuentran excluidas de la aplicación directa del régimen general de responsabilidad por falta de servicio previsto en la Ley $\mathrm{N}^{\circ} 18.575$. Como estos servicios públicos son, con bastante frecuencia, protagonistas de problemas de responsabilidad extracontractual, la pregunta acerca del régimen aplicable se plantea recurrentemente.

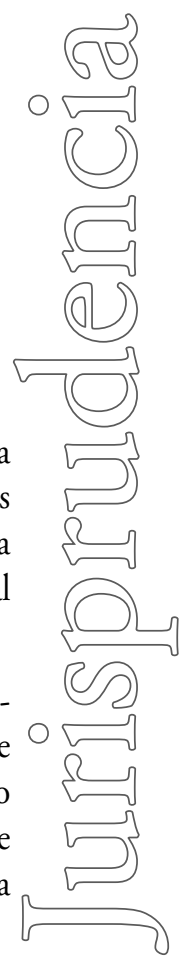

2. Para enfrentar esta cuestión, la Corte entiende que la noción de culpa contenida en el Código Civil, específicamente en el artículo 2314 -que configura la más general de las reglas de responsabilidad extracontractual instituidas en el derecho chileno-cubre también fenómenos de funcionamiento defectuoso y organización deficiente de un servicio público. En otros términos, aun sin reconocimiento legal expreso, la falta de servicio podría ser constatada y declarada por el juez en aplicación de las reglas tradicionales de responsabilidad civil.

Por eso, el pronunciamiento tiene importancia tanto para el derecho administrativo como para el derecho civil. Para este último supone admitir de un modo bastante oficial que la culpa está desprovista de sicologismo. El fallo trae a colación la doctrina comparada sobre la culpa objetiva, principalmente de origen francés (cabe recordar que en el modelo francés los infantes son capaces de una culpa cuyo umbral sicológico es prácticamente nulo). El reproche envuelto en la culpa del Código Civil, entonces, supone simplemente inobservancia de deberes. Precisamente ahí está la importancia que reviste el fallo para el derecho administrativo: en la equivalencia práctica entre culpa y falta de servicio.

3. En cuanto a los resultados, esta decisión no es demasiado sorprendente. Por diversas razones, era probable que la Corte se pronunciara en el sentido que lo ha hecho. Ante todo, no cabe descartar que el motivo que justifica el razonamiento del fallo se encuentre en la argumentación del demandante: las circunstancias del caso hacían plausible el acogimiento de la demanda, y corregir sus planteamientos 
hubiera supuesto el riesgo de una solución inicua. En todo caso, no es una solución novedosa, porque con anterioridad a la recepción legislativa del concepto de falta de servicio a fines de la década de 1970, la jurisprudencia recurría ocasionalmente al Código para resolver problemas de índole administrativa. Por último, y sobre todo, una parte importante de la doctrina, encarnada en el profesor Pierry, ya se había inclinado en el mismo sentido del fallo ${ }^{1}$, y resultaba imaginable que en el desempeño de su magistratura suprema este profesor consiguiese influir con sus teorías en la opinión de la Corte.

4. ¿La decisión es inocua?

En las circunstancias del caso, la noción civil de culpa permite atribuir directamente al Estado una falta de servicio cometida al interior de los cuarteles. En concreto, el hecho dańoso consiste en un disparo efectuado durante la práctica de ejercicios de instrucción militar, llevados a cabo con municiones de guerra, contrariando instrucciones en el sentido de utilizar cartuchos de fogueo. Así, la solución adoptada por los jueces del fondo enfrenta satisfactoriamente el problema planteado, porque la culpa constituye desde todo punto de vista una falta vinculada al ejercicio mismo de funciones militares. Porque el hecho demuestra desorganización, desobediencia ante instrucciones internas y fiscalización insuficiente, se trata de una falta de servicio.

Con todo, el principal riesgo que suscita una fundamentación centrada en el Código Civil está en la tentación de recurrir a las reglas civiles también para resolver el problema de la responsabilidad individual del funcionario. No puede predecirse con exactitud los problemas que es susceptible de generar esta orientación jurisprudencial, particularmente en la argumentación estratégica que despliegue la defensa fiscal con miras a evitar condenas. Con todo, cabe esperar que, así como ha ocurrido en este caso, en el futuro los demandantes se limiten a imputar genéricamente una falta de servicio de tipo anónima; en la medida que el demandado no tiene de su mano la posibilidad de provocar un litisconsorcio pasivo (arrastrando así a sus agentes al juicio), se evitará discutir la cuestión de la responsabilidad individual del funcionario.

5. Por encima de las consecuencias que la sentencia trae para el caso concreto, la respuesta de la Corte es de la mayor sensatez. Nunca se insistirá lo suficiente en el carácter puramente textual del problema de la responsabilidad del Estado por hecho de las instituciones armadas y policiales: nadie discute que el Estado debería responder en términos similares, si no idénticos, a la forma en que lo hace respecto del conjunto de los servicios públicos. Ninguna razón justifica sustraer a instituciones tan típicamente administrativas como las integrantes de la administración militar y policial, del régimen de responsabilidad que el derecho positivo asigna a los organismos administrativos. Por eso, la orientación

Esta tesis se encuentra planteada ya en el temprano estudio "La responsabilidad extracontractual del Estado", Anuario de Derecho Administrativo 1 (1976), p. 471. 
que ha seguido la jurisprudencia, y que por ahora culmina con esta sentencia, ha consistido permanentemente en minimizar las restricciones textuales del régimen de la falta de servicio, a veces incluso pasándolas por alto ${ }^{2}$, para extenderlo sin ley expresa a esas instituciones.

El resultado de esta orientación tiene un sentido didáctico fuerte. Al expandirse las categorías generales de la responsabilidad, los casos especiales quedan reducidos al carácter de meras excepciones, que siempre requieren una justificación suplementaria. De algún modo, el derecho se simplifica cuando las categorías generales conquistan nuevos terrenos. Y es justamente esa simplificación uno de los méritos principales de la sentencia.

6. Aparte de este resultado analítico, consecuencias ideológicas importantes derivan de la sentencia. La extensión del régimen de la falta de servicio, aun cubierta por la terminología propia del derecho civil, es presentida como una solución justa. El fallo no oculta su satisfacción por la respuesta adoptada: el régimen de la falta de servicio, de origen francés, constituye en opinión de la mayoría de los autores, "la mejor solución lograda por el derecho, para asegurar un debido equilibrio entre los derechos de los particulares y los intereses públicos" (cons. 14).

7. De paso, la sentencia resuelve ciertos aspectos problemáticos de la definición de la falta de servicio ${ }^{3}$, mediante el establecimiento de criterios que refuerzan el alcance general de este régimen de responsabilidad. En la jurisprudencia reciente, en parte impulsada por cierta doctrina, habían surgido pronunciamientos que parecían restringir el alcance de la falta de servicio, tanto en atención a la calidad de las víctimas, como a las actividades de la administración. La defensa fiscal no tardó en aprovechar estas aparentes fisuras del régimen general, simplemente para intentar eludir la responsabilidad del Estado. El fallo rechaza estos planteamientos, restituyendo a la falta de servicio su vocación general.

8. Así, en lo que toca a la calidad de las víctimas, la sentencia indica que "la noción de falta de servicio debe ser analizada independientemente y no en relación a los posibles usuarios del servicio público, pudiendo comprometerse la responsabilidad del Estado por falta de servicio que cause dańo a terceras personas que no sean

2 V. entre otros: CA Santiago, 10.10.2000, cl Zambrano García, Gaceta Jurídica 245 (2000), p. 169, Rev. Derecho - Consejo de Defensa del Estado 2 (2000) p. 275, Legal Publishing $N^{\circ} 21106$ (responsabilidad por falta de servicio acogida, proveniente de daños causados en un hospital de Carabineros); 3er Juzg. Civil Concepción, 26.08.2002, Concha Segura y otros c/ Fisco (disparo policial para disipar una turba; el fallo habla de falta de servicio, sin citar el art. 42), conf. CA Concepción, 19.08.2003, CS, 24.12.2003, Legal Publishing N²9444; CA Valparaiso, 17.09.2003, Meza Figueroa c/Fisco (daños provocados por un radiopatrullas de carabineros; rechazo de la demanda en el fondo, sin cuestionar la aplicación del régimen de la falta de servicio), conf. CS, 13.07.2004, Legal Publishing $N^{\circ} 30439$. Y, refiriéndose al concepto de falta personal (cuya consagración normativa también se halla en el art. 42 de la Ley 18.575), CS, 26.09.2000, Fisco c/Valencia Barahona, Legal Publishing $N^{\circ} 17222$ (repetición contra funcionario policial), o CS, 20.03.2006, Vargas Grandón cl García Hernández, Gaceta Jurídica (2006) 309.59 (brutalidades policiales).

3 Que habían sido denunciados con anterioridad: J. M. Valdivia, "Nuevas fronteras de la falta de servicio", Gaceta Jurídica 301 (2005), p. 7. 
usuarias del órgano estatal que la cometió” (cons. 12 in fine).

En esta parte, el fallo se entiende mejor en la medida que se lo confronte con varias decisiones que asumían el régimen de la falta de servicio como privativo de una categoría específica de víctimas: los usuarios de los servicios públicos. Es más, en algunos casos la jurisprudencia había entendido que el régimen de la falta de servicio era ajeno a los problemas de responsabilidad que surgen entre la administración y sus agentes o colaboradores ${ }^{4}$, de modo que en un caso como el presente, en que el daño alcanzaba a un conscripto del servicio militar, no hubiera encontrado respuesta mediante el derecho común de la responsabilidad pública.

Como ha sido analizado con mayor detalle en otro lugar, esa tendencia restrictiva sólo tendría sentido si la distinción entre categorías de víctimas sirviese para identificar a aquellas que, por su posición de especial vulnerabilidad, deberían gozar de una garantía excepcional frente a los riesgos provenientes del servicio público, respondiendo éste sin culpa (o sea, sin necesidad de demostrar una falta de servicio). No obstante, salvo en casos marginales ${ }^{5}$, en la experiencia chilena el argumento indicado había servido sólo para rechazar la responsabilidad del Estado, mostrándose como un razonamiento injusto ${ }^{6}$. El fallo Seguel zanja esta cuestión en forma adecuada, descartando que la distinción entre usuarios y terceros, e incluso agentes o colaboradores de la administración (que era la categoría de víctimas pertinente en la especie), sea relevante para definir la falta de servicio ${ }^{7}$.

9. Por otra parte, en cuanto rechaza el argumento de que la falta de servicio debería descartarse "al no prestar servicio alguno a la comunidad" el organismo en cuestión (cons. 12), la sentencia disipa un equívoco bastante difundido en el medio nacional. Una idea recurrente entiende que la expresión "falta de servicio"

V. p. ej., CS 08.05.2002, Figueroa Gallardo c/ Fisco, Rev. Derecho del Consejo de Defensa del Estado, $N^{\circ} 7$ (2002), Legal Publishing $N^{\circ} 25336$. En este caso un funcionario fiscal muere mientras ejecuta tareas de su oficio (chofer), muerte que los demandantes imputan a una falta de servicio de la dirección de vialidad del MOP, en que la víctima laboraba. La Corte Suprema indica que "en este campo, no tendría mayor cabida la responsabilidad del Estado por falta de servicio" (cons. 19).

5 Así, CS, 26.01.2005, Bustos Riquelme cl Fisco, Gaceta Juridica 297 (2005), p. 58; y CS, 19.10.2005, Caro Silva cl Fisco, Gaceta Jurídica 304 (2005) p. 70. La responsabilidad es acogida aquí haciéndose mención explícita al riesgo creado por el Estado frente a sus colaboradores.

6 El ejemplo más dramático concierne a una paseante que queda inválida al recibir un disparo proveniente de un gendarme penitenciario, efectuado tras la fuga de un recluso, en las afueras de la cárcel de Tocopilla. En CS, 27.08.2003, Arévalo Bascuñán c/ Fisco, rol 3876-2001, se deniega reparación a la víctima, estimándose que Gendarmería de Chile no presta ningún servicio en forma directa a la comunidad (ni a fortiori a la propia víctima).

Naturalmente, este razonamiento no necesariamente supone que la distinción entre categorías de víctimas sea inapropiada para forzar el surgimiento de otro tipo de regímenes de responsabilidad, eventualmente fundados en la idea de riesgo. Tratándose de funcionarios públicos, por lo menos, sigue vigente la normativa específica sobre accidentes del trabajo; incluso los conscriptos gozan de ciertas prestaciones en caso de accidentes de servicio (Ley 18.948, Ley orgánica constitucional de las Fuerzas Armadas, arts. 66 s.; DFL 1, de Guerra, de 1997, Estatuto del personal de las Fuerzas Armadas, arts. 231 s.; DL 2306, de 1978, Normas sobre reclutamiento y movilización de las Fuerzas Armadas, art. 16.). En tanto estas prestaciones tienen por objeto la reparación de perjuicios, deberían tenerse en cuenta en sede de responsabilidad. 
podría sustituirse por "omisión de servicio" o algo parecido ${ }^{8}$. Implícitamente, ese razonamiento restringe el ámbito de aplicación del régimen de la falta de servicio, pues sólo el ejercicio de aquellas actividades administrativas que se traducen en el otorgamiento de prestaciones (susceptibles de fallar) podría dar origen a una responsabilidad por falta de servicio.

La identidad que el fallo Seguel establece entre la falta de servicio y el concepto civil de negligencia pone atajo a esta extraña teoría: en definitiva, en materia de responsabilidad extracontractual cuenta ante todo determinar si el daño no ha debido producirse, lo que exige analizar la observancia de los deberes de cuidado (en el ámbito público, deberes de servicio) que se imponían al agente. Es obvio que, en cuanto especie de culpa, la falta de servicio se comete tanto por acción como por omisión. Por eso, es erróneo entender que la falta de servicio se configure cuando un servicio no se presta o se presta mal o tarde; al contrario, ésta aparece cuando el servicio público, entendido como unidad orgánica, "no funciona, debiendo hacerlo, cuando funciona irregularmente o tardíamente" (en palabras del fallo). Se trata de reconocer "una deficiencia o mal funcionamiento del servicio en relación a la conducta normal que se espera de él”, en función de parámetros normativos definidos por la ley o el reglamento, o construidos por el juez en atención a la naturaleza de las funciones públicas. La falta de servicio es, pues, una especie de culpa.

10. La sentencia efectúa en este punto categóricas aseveraciones respecto del origen del régimen de responsabilidad por falta de servicio. La Corte indica que mediante la recepción del criterio de la falta de servicio, la ley “incorporó al Derecho Público chileno el sistema de responsabilidad extracontractual del Estado elaborado por el derecho administrativo francés, principalmente a través de la jurisprudencia del Consejo de Estado" (cons. 14). En cuanto alude a una "incorporación" del derecho francés al derecho chileno, la afirmación es sin duda excesiva, pero lo que persigue la Corte es simplemente restablecer el origen de los conceptos, para contrarrestar una tendencia doctrinal que parece querer reescribir la historia de estas nociones, prescindiendo de las opciones explícitas del legislador en materia de responsabilidad pública.

Ahora bien, recordar el origen jurisprudencial del derecho positivo de la responsabilidad pública hace posible una última reflexión. Un desafío pendiente en la materia apunta a recoger la experiencia comparada en su aspecto metodológico: la falta de servicio debe regir en el ámbito de las fuerzas armadas y de orden porque es razonable que así sea, no porque el Código Civil lo establezca.

8 Este planteamiento, cuyo motor está en la negación del origen francés de la falta de servicio, aparece recogido en los escritos recientes de E. Soto K. P. ej., "Falta de servicio ¿̨égimen general de la responsabilidad del Estado/Administración en Chile? (El derecho ‘arte de magia?)", in Conferencias Santo Tomás de Aquino 2006, La responsabilidad del Estado-Administración, Santiago, Universidad Santo Tomás, 2006 y Gaceta Juridica 317 (2006). 
